If the anti-reflux mechanism is maintained in case of an atonic bladder with a capacity of $3000 \mathrm{ml}$., the upper urinary tracts may be without any pathological changes.

In summarising, one can say that in all cases of neurogenic disturbances of micturition the radiological examination of the upper urinary tract belongs to the routine examinations. The deferrent urinary tracts form a unit so that bladder diseases may affect the upper urinary tracts. This finding which has always been stressed by Alken (I968) also applies to the neurogenic disturbances of micturition.

\title{
REFERENCES
}

AdLer, A. (1920). Dtsch. Ztschr. Nervenheilkunde, 65, 72.

ALKEN, C. E. (I968). Leitfaden der Urologie, Thieme-Verlag, Stuttgart.

Allert, M. L., BRESSEL, M. \& SöKeland, J. (1968). F. Urol. belge (not yet printed).

Bors, E. \& Turner, R. D. (I967). In The Neurogenic Bladder, ed. Boyarsky, S. Baltimore:

The Williams and Wilkins Company.

Guttmann, L. \& Frankel, H. (I966). Int. F. Paraplegia, 4, 63.

GuttmanN, L. (1968). Conference on Neurogenic Bladder, Homburg, in press.

Litvak, A. S., ReA, M. \& BAKER, J. (I968). F. Urol. 99, 462.

MeYer, E. (I928). Handbuch der Urologie. Edition by A. V. Lichtenberg, Berlin. F.

Voelcker, Halle, A. Wildbolz, Bern. Third volume. Berlin: Verlag J. Springer.

Talbot, A. S., Mahoney, E. M., Jarret, J. E. \& Cobb, E. (I967). Paraplegia, 5, 94.

Walsh, J. J. (1968). Int. F. Paraplegia, 2, 74.

\section{STONE FORMATION IN PARAPLEGIA}

\author{
By P. H. Smith, M.B., F.R.C.S., J. B. Cook, M.D., M.R.C.P., and \\ W. G. ROBERTSON, B.Sc. \\ Spinal Injuries Unit, Pinderfields General Hospital, Wakefield, and M.R.C. Mineral \\ Metabolism Research Unit, The General Infirmary at Leeds, England
}

\section{INTRODUCTION}

Previous studies have established that immobilisation is associated with hypercalciuria and with a slight increase in the urine volume and the urine $\mathrm{pH}$, that aggregations of crystals detectable radiologically may be seen within seven to ten days of immobilisation, and that the majority of stones formed after immobilisation are evident within I 8 months and are mainly phosphatic in nature (Leadbetter and Engster, I945; Dietrick, Wheldon and Shorr, I948; Wheldon Dietrick and Shorr, I949; Comarr, I955; Elliot and Todd, I96I).

The aetiological factors have been reviewed by many authors and include immobility, urinary stasis, hypercalciuria, a high urinary $\mathrm{pH}$ and urinary infection (Pyrah and Fowweather, 1938; Pulvertaft, 1939; Flocks, 1945; Leadbetter and Engster, 1945; Taylor, Alcock and Hildes, 1956; Plum, 1958; Elliot and Todd, I96I).

The adoption of a regime which involves regular turning, early mobilisation, a high fluid intake, the administration of acidifying agents and urinary antiseptics and the prevention and prompt treatment of urinary infections has resulted in a fall in the incidence of renal stone formation in patients with spinal cord injury from 20 to 30 per cent. at the end of the second world war (Riches, I943a; Prather, 
I947), to less than I per cent. ten years later (Comarr, I955), and it may be thought that stone formation in the upper urinary tracts of the paralysed patient is now an avoidable hazard, though bladder stones and catheter encrustations and deposits are still frequently seen.

Patients who do form stones frequently have a high urinary $\mathrm{pH}$ associated with a urine infection due to $\mathrm{B}$. proteus. A high urinary $\mathrm{pH}$ may also be found in association with acquired renal tubular acidosis and has been reported as a result of metabolic alkalosis in groups of patients with poliomyelitis treated for long periods of time with artificial ventilation who also had a high incidence of stone formation (Blossom and Affeldt, I956; Taylor, Alcock and Hildes, 1956; Elliot and Todd, I96I). These facts, considered in relation to the precipitous fall in the incidence of stone formation after spinal injury which occurred in the decade following the general introduction of antibiotic therapy, suggested to us that the urinary $\mathrm{pH}$ may well be the most important of the many aetiological factors.

New patients admitted immediately after injury to the Spinal Injuries Unit at Pinderfields General Hospital, Wakefield, between November 1966 and August 1967, have been studied in a prospective survey, the investigations being designed to show the role of urinary $\mathrm{pH}$ and urinary infection in stone formation in the immobilised patient. Since that time we have also considered ways in which the formation of bladder stones may be prevented and have carried out a preliminary survey of the incidence of renal tubular acidosis in 33 patients after spinal injury.

\section{METHOD}

In the initial investigation 24-hour samples of urine were collected from every patient at weekly intervals for the first 13 weeks after injury. Each collecting bag contained I g. streptomycin and I g. chloramphenicol to prevent bacterial multiplication and subsequent alteration of $\mathrm{pH}$. Urinary $\mathrm{pH}$ was measured with a glass electrode-using a Radiometer $\mathrm{pH}$ Meter 27. Total calcium was measured by an Auto-Analyser technique (McFadyen, Nordin, Smith, Wayne and Rae, I965); magnesium by atomic absorption flamephotometry (Dawson and Heaton, I96I); ammonia by the method of Chaney and Marbach (1962); oxalate by the method of Zarembski and Hodgkinson (1965a, b); phosphorus and creatinine by the standard Auto-Analyser techniques; and the activity products of octocalcium phosphate, calcium oxalate and magnesium ammonium phosphate were calculated by the computer procedure of Robertson, Peacock and Nordin (I968).

A plain X-ray of the urinary tract was taken on admission and monthly thereafter followed by an intravenous pyelogram when the patient was mobilised. Whenever a urinary infection was suspected on clinical grounds a specimen of urine was collected and antibiotic therapy started immediately.

In the second investigation the diagnosis of renal tubular acidosis was established by the failure of the urinary $\mathrm{pH}$ to fall below 5.4 after an acid load of $7 \mathrm{~g}$. gelatine-coated capsules of ammonium chloride (Davies and Wrong, I957).

\section{RESULTS}

Thirteen patients were studied in the first investigation and complete results are available in eight. The hypercalciuria of immobilisation (expressed as the percentage change in the calcium/creatinine ratio) was demonstrated in both the 
paraplegic and tetraplegic patients. The calcium excretion tended to return to normal as the paraplegic patients were mobilised (fig. I) but remained high in the tetraplegic patients who did not become mobile during this study (fig. 2).

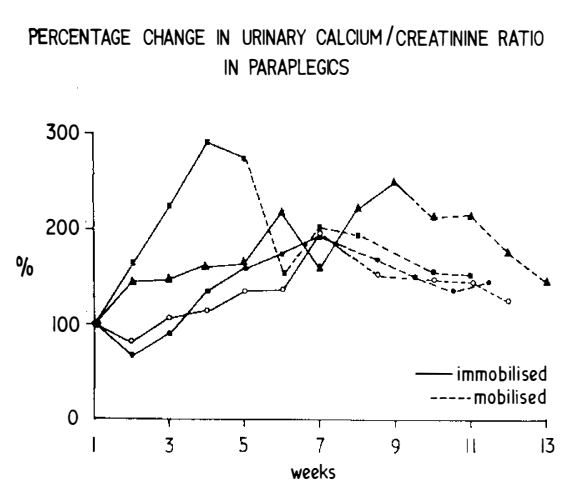

FIG. I
PERCENTAGE CHANGE IN URINARY CALCUM /CREATININE RATIO

IN TETRAPLEGICS

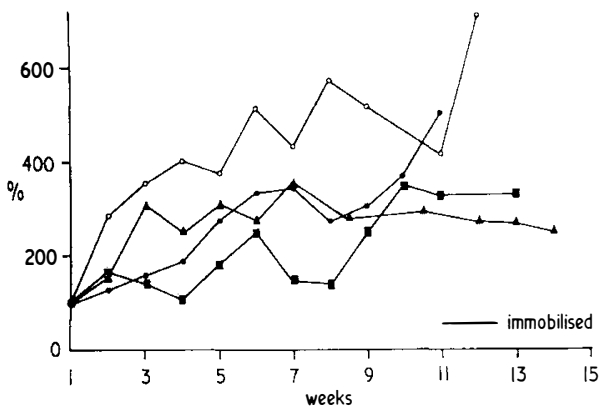

FIG. 2

Fig. I-To show the hypercalciuria of immobilisation after the onset of paraplegia.

Fig. 2-To show the hypercalciuria of immobilisation after the onset of tetraplegia.

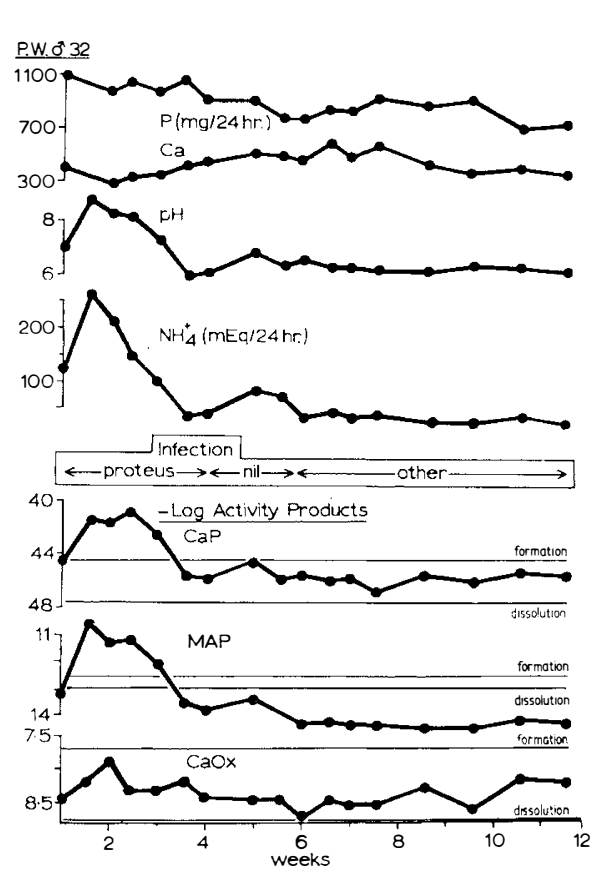

FIG. 3

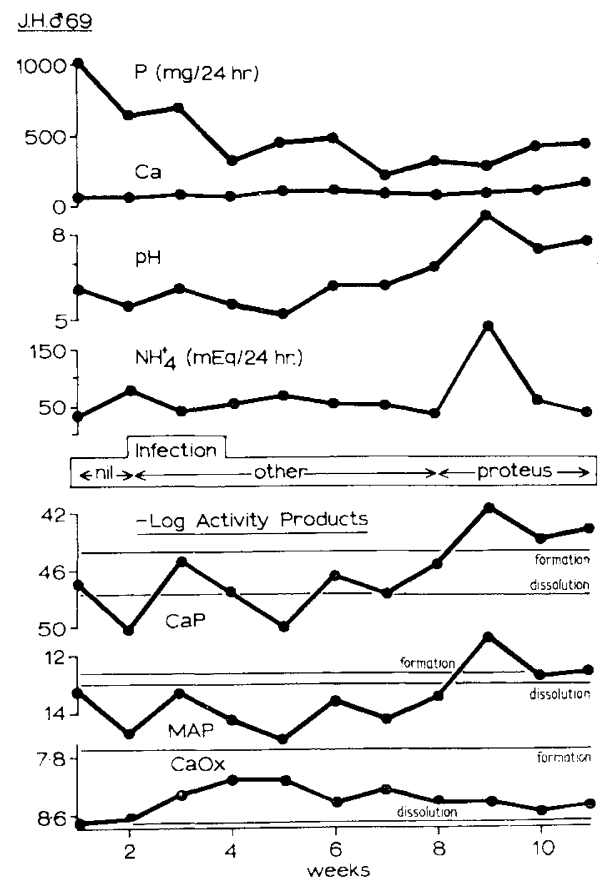

FIG. 4

To show the effect of $\mathrm{B}$. proteus infection of the urinary tract on the urinary $\mathrm{pH}$, ammonia and activity products of octocalcium phosphate and magnesium ammonium phosphate. 
The investigations showed also the marked effects of urinary infection due to $\mathrm{B}$. proteus on the solubility of octocalcium phosphate and magnesium ammonium phosphate in urine. These changes are illustrated in Figures 3 and 4 and show the week by week variations in the urines of two of these patients.

The urinary $\mathrm{pH}$ was on the high side of normal throughout the period of study and the breakdown of urea due to proteus infection of the urinary tract caused a further marked rise in the urinary $\mathrm{pH}$ and in the urinary ammonium excretion. Infections with other organisms seemed to have less effect. As the urinary $\mathrm{pH}$ and urinary ammonium excretion rose the solubilities of octocalcium phosphate and magnesium ammonium phosphate decreased greatly. This is shown by the rise in the activity products above the level of the formation products and as mentioned by Robertson et al. (1968), in this area the urine is supersaturated to such an extent that crystal formation would be expected to occur even in the absence of a nucleus. During these periods the calcium oxalate product which is not $\mathrm{pH}$ dependent changed only slightly. The fact that none of the patients in this series formed stones is, we believe, due to the rapid control of the dangerous situation produced by infection by the free use of antibiotics and by mobilisation at the earliest possible stage.

Though it may be hoped that renal stone formation occurring in the first few months after injury will become increasingly rare, it must be admitted that such stones may be seen several years after spinal injury. A previous article (Cook and Smith, 1968) suggested that stone formation in the upper renal tract may be less commonly seen where there is free drainage of urine. In certain patients, however, this can be satisfactorily achieved only by permanent urethral catheterisation or by the much more extensive procedure of urinary diversion.

It is well known that an indwelling urethral catheter is rarely associated with a sterile urine and frequently causes small flakes of stone-catheter stones-within the bladder or encrustations within the catheters which may then block within a few days. These hazards can be avoided in the early weeks after spinal injury by the use of intermittent catheterisation which has yielded excellent results (Guttmann and Frankel, I966). On the other hand it is not yet possible to provide this standard of care in all paraplegic units and there is no doubt that some patients do use indwelling catheters after mobilisation. It has been our own experience that urinary infection has been seen all too frequently during intermittent catheterisation though the incidence of bladder stones is, of course, much lower than one sees with an indwelling catheter. Because of a shortage of nursing and medical staff we modified the technique of intermittent catheterisation so that it was always possible for catheters to be inserted by trained nursing staff. Our technique was as follows:

I. The patient was catheterised at 8 p.m. and the catheter left indwelling overnight, during which time the patient was required to drink $\mathrm{I} \frac{1}{2}$ litres of fluid. This we felt to be an advantage in that it obviated the necessity for restriction of fluids over the 24 hours.

2. At 9 a.m. the catheter was removed, the bladder filled and

3. at 2 p.m. the catheter was inserted, the bladder drained again and the catheter removed. The bladder filled up and was drained again at 8 p.m. leaving the catheter in position.

This reduced the number of catheterisations required by 50 per cent. and allowed a higher intake of fluid than would otherwise have been possible. It was 
still apparent, however, that the majority of patients developed a urinary infection within three weeks of their admission.

The onset of such an infection often requires a period of indwelling catheterisation and is too often followed by the development of small catheter stones (fig. 5) and encrustations irrespective of whether the catheter is made of latex or plastic (fig. 6). Now, however, silastic catheters are becoming available and it may

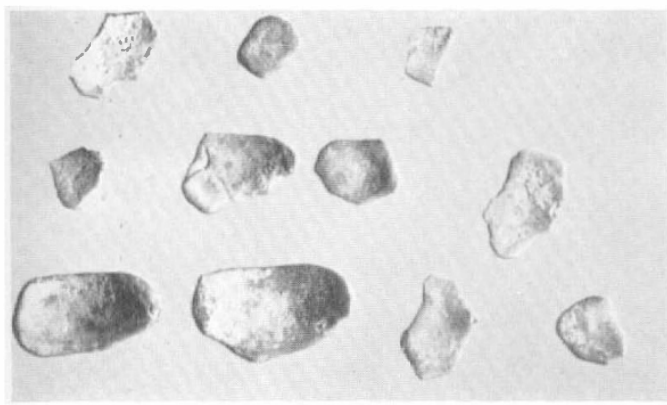

FIG. 5

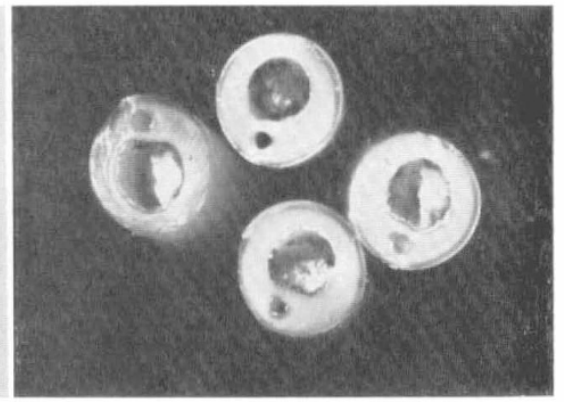

FIG. 6

Fig. 5-Small egg-shell stones formed around the balloon of a latex Foley catheter.

Fig. 6-Transverse sections of plastic catheters to show encrustations.

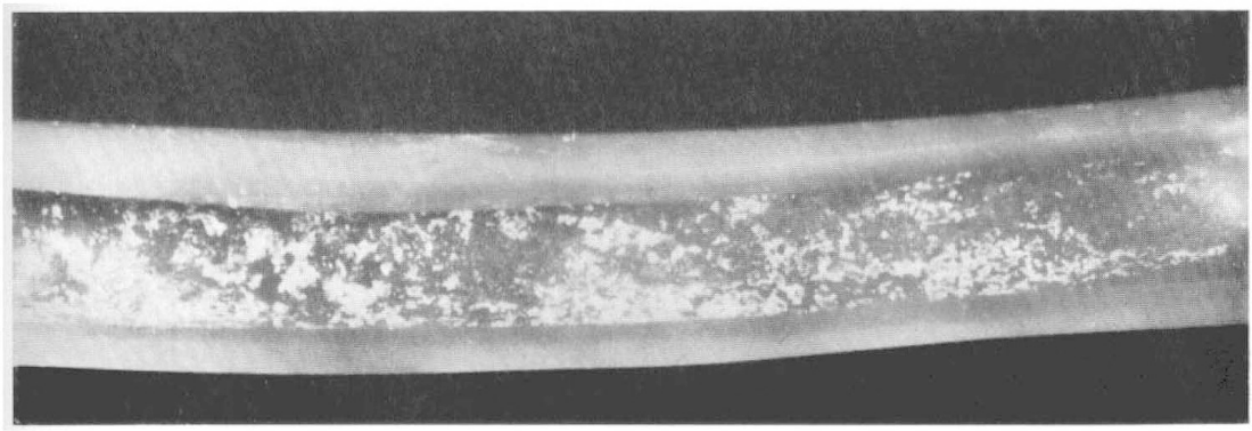

FIG. 7

Section of silastic nephrostomy catheter removed after six weeks showing minimal crystal deposition.

be that these will be more successful if suitable means of retaining them within the bladder can be found (fig. 7). All these catheters must, however, lie within the urethra and are thus liable to cause urinary infection.

Because of this potential hazard we have recently undertaken a short clinical trial of a plastic catheter designed for suprapubic use by Bard-Davol Limited (the suprapubic angiocath, I966 S.P.). This consists of a 6 in. or 8 in. plastic cannula with a hollow bevelled trocar which is inserted with ease into the distended bladder through a mid-line stab over the upper part of its anterior wall after the skin has been shaved and cleaned, and may remain in position for several weeks (figs. 8 and 9). You may consider this merely a revival of a well-tried technique (Riches, $1943 b$ ), but we believe it to be of value in those units where intermittent catheterisation by the medical staff is impossible. It has the advantages that it can 


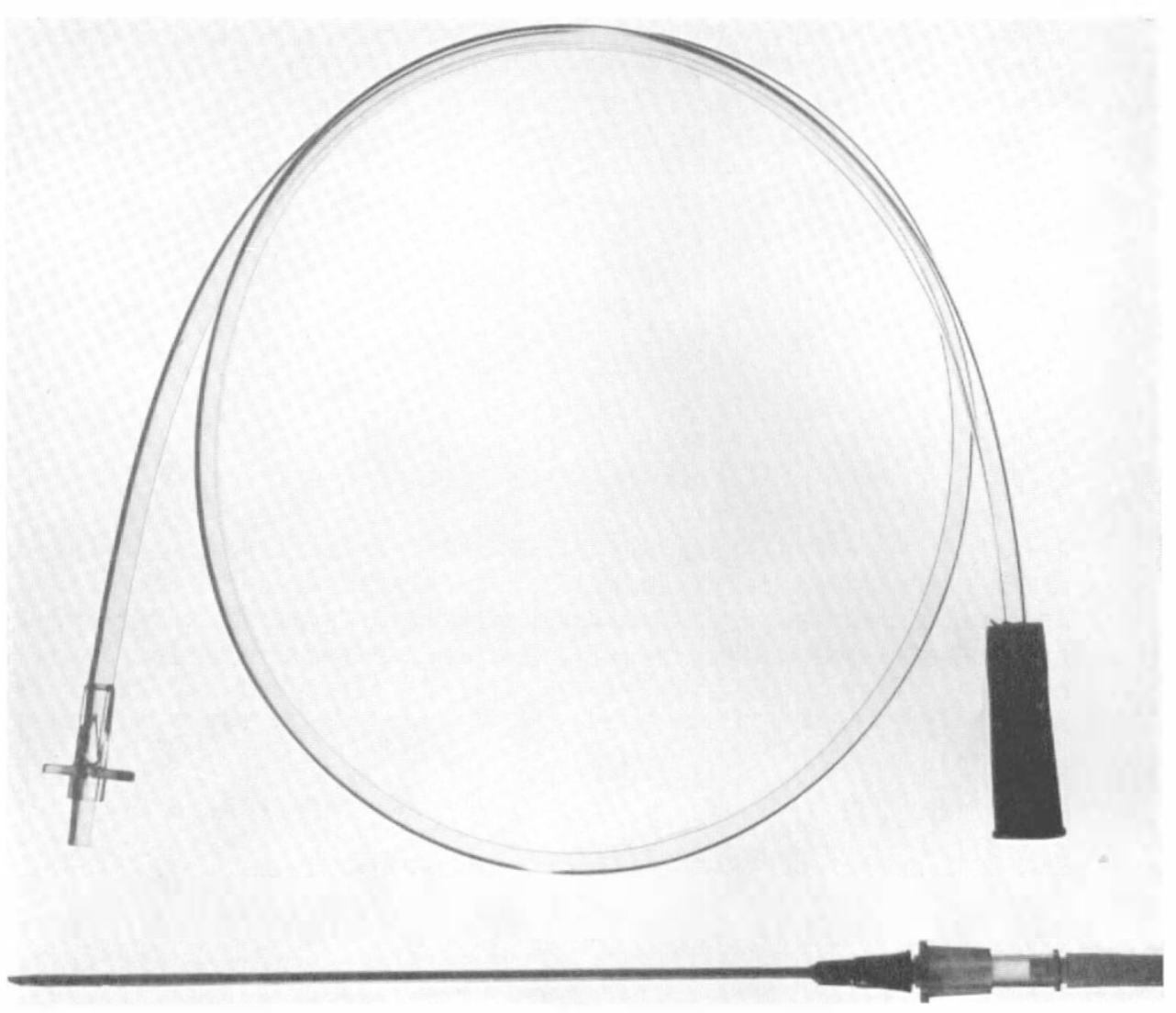

FIG. 8

The Suprapubic Angiocath with drainage tube (Bard-Davol Ltd.).

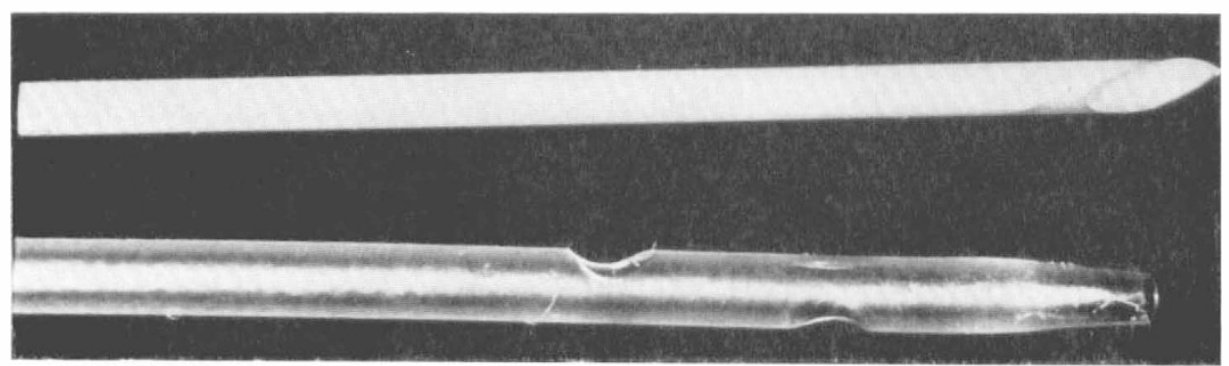

FIG. 9

Detail of Suprapubic Angiocath (Bard-Davol Ltd.) to show hollow bevelled trocar. This fits within the plastic cannula which has several small holes near its tip. 
be inserted under sterile conditions by a doctor, can then remain undisturbed, decreases the incidence of urinary infection, avoids any urethral instrumentation and may be adequate for the whole period of urinary retention following spinal injury. It has the disadvantages, however, that it may kink, usually at its junction

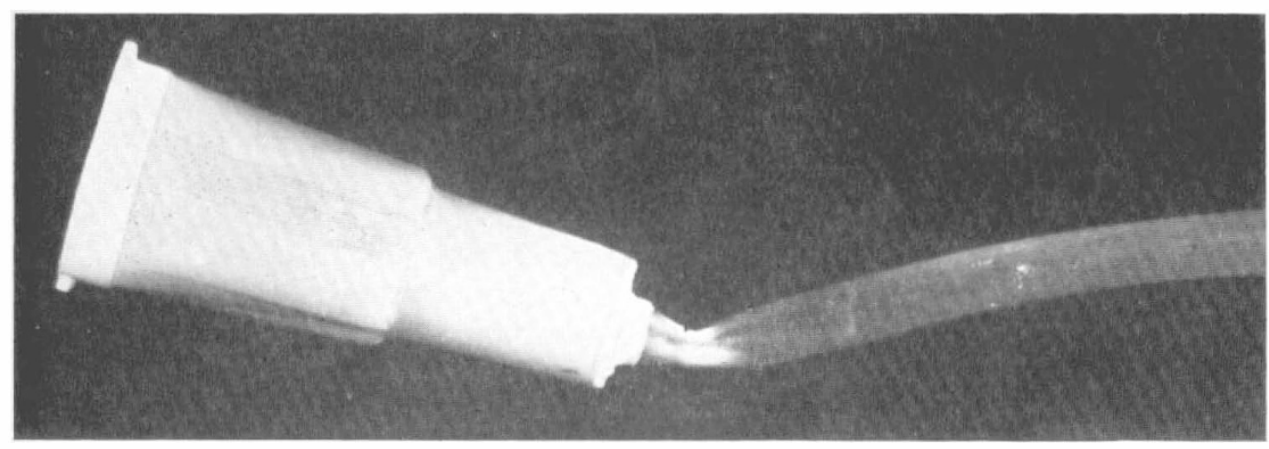

FIG. IO

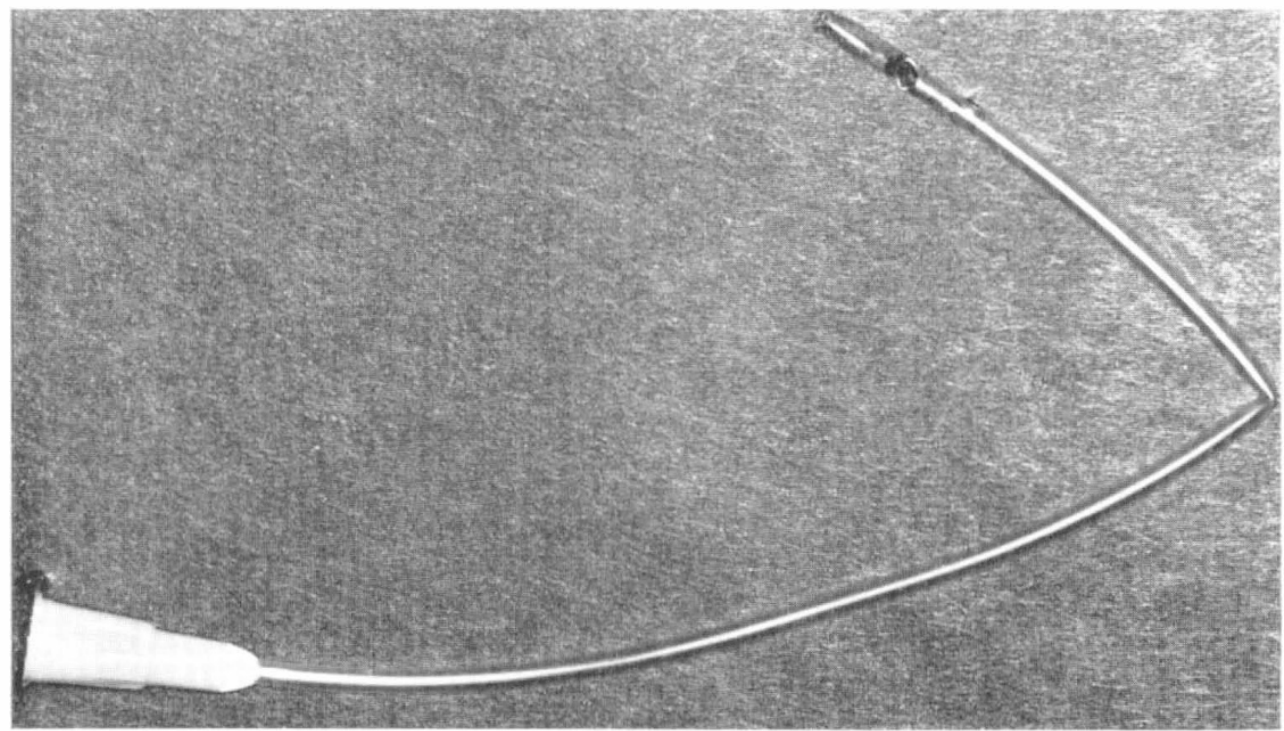

FIG. II

Figs. IO and I I-To show kinks in cannulae at the junction with the skin (fig. IO) and within the bladder (fig. II).

with the skin but sometimes within the bladder, faults which still have to be rectified (figs. IO and II).

We have used this method of urinary drainage in 12 male patients and the results are as follows:

I. Eighteen cannulae were used in 12 patients. Though six of them blocked due to kinks within two days, each cannula lasted an average of 13 days (o to 45 days). 
2. Five patients were never catheterised but the other seven eventually had a urethral catheter, in each case because a member of staff was uncertain of the technique for re-insertion of the cannula after it had blocked due to a kink.

3. Six patients had sterile urine throughout $(6,8, \mathrm{I}$ I, I $8,20,3 \mathrm{I}$ days). Infection was first seen in the other patients after I9 to 30 days.

None of the cannulae showed significant deposits when they were removed, and no patient developed a suprapubic fistula or extravasation of urine. We have found these catheters a considerable help to both medical and nursing staff.

Recently Cochran, Peacock, Smith and Nordin (1968) have shown that renal tubular acidosis due to chronic pyelonephritis may be an additional factor in renal stone disease. We have, therefore, carried out a preliminary survey of the incidence of renal tubular acidosis in 33 patients after spinal injury. Twelve of these patients appeared to be unable to excrete urine below $\mathrm{pH} 5.4$ after an acid load of $7 \mathrm{~g}$. gelatin-coated ammonium chloride capsules. In six of these patients the significance of these results is in doubt because of a persistent B. proteus infection of the urine, but the other six patients had sterile urine or coliform infections which do not usually affect the urinary $\mathrm{pH}$. One of these patients formed a bladder stone. The blood urea was $<25 \mathrm{mg}$. per cent. in all these patients and the intravenous pyelogram did not show evidence of chronic pyelonephritis. The significance of these findings is as yet quite unknown but the possible association of renal tubular acidosis as a complication of pyelonephritis suggests that this condition merits further study in the paraplegic patient.

\section{SUMMARY}

Evidence is produced to suggest that rise in the urinary $\mathrm{pH}$ is likely to be the chief factor in the formation of urinary stones in the paraplegic patient and it is suggested that the introduction of antibiotic therapy has been responsible for the fall in the incidence of stone formation which followed the second world war.

Despite this, small bladder stones and catheter encrustations are still commonly seen and we believe that the use of suprapubic plastic or silastic catheters in the acute phase merits further investigation.

Comments are also made on the possibility of renal tubular acidosis occurring after spinal injury.

\section{ACKNOWLEDGEMENTS}

We should like to acknowledge the support of the Multiple Sclerosis Society of Great Britain and Northern Ireland throughout this study, to thank Mr. J. Mullins and other members of the nursing staff of the Spinal Injuries Unit for their invaluable help and to thank the Department of Photography, St. James's Hospital, Leeds, for the illustrations.

We are indebted to Messrs. J. \& A. Churchill Limited for permission to publish Figures I-4 which originally appeared in Renal Stone Research Symposium, Leeds, April, I968.

\section{REFERENCES}

Blossom, R. A. \& Affeldt J. E. (1956). Amer. F. Med. 20, 77.

Chaney, A. L. \& Marbach, E. P. (I962). Clim. Chem. 8, I 30.

Cochran, M., Peacock, M., Smith, D. A. \& Nordin, B. E. C. (I968). Brit. med. F. I, 72 I. ComarR, A. E. (I955). F. Urol. 74, 447.

Cook, J. B. \& SMITH, P. H. (1968). Int. F. Paraplegia, 6, I I.

Davies, H. E. F. \& Wrong, O. (I957). Lancet, 2, 625. 
Dawson, J. B. \& Heaton, F. W. (I95I). Biochem. F. 80, 99.

Dietrick, J. E., Wheldon, G. D. \& Shorr, E. (I948). Amer. F. Med. 4, 3.

Elliot, J. S. \& TODD, H. E. (I96I). F. Urol. 86, 484.

Flocks, R. H. (1945). F. Urol. 53, 427.

Guttmann, L. \& Frankel, H. (I966). Int. F. Paraplegia, 4, 63.

LEADBETTER, W. R. \& ENGSTER, H. E. (I945). F. Urol. 53, 269.

McFayden, I. J., Nordin, B. E. C., Smith, D. A., Wayne, D. J. \& RaE, S. L. (1965). Brit. med. $\mathcal{F} . \mathbf{1}, \mathrm{I} 6 \mathrm{I}$.

Plum, F. (1958). F. Amer. Med. Ass. 168, 1302.

Prather, G. C. (I947). F. Urol. 57, I097.

Pulvertaft, R. G. (1939). F. Bone and foint Surgery, 21, 559.

Pyrah, L. N. \& Fowweather, F. S. (I938). Brit. F. Surg. 26, 98.

RICHES, E. W. (1943a). Brit. F. Surg. 3I, I35.

RICHES, E. W. (I943b). Lancet, 2, I 28.

Robertson, W. G., Peacock, M. \& Nordin, B. E. C. (1968). Clin. Sci. 34, 579.

Taylor, J. E., Alcock, A. J. W. \& Hildes, J. A. (1956). Canad., ed. Ass. F. 75, 29.

Wheldon, G. D., Dieitrick, J. E. \& Shorr, E. (I949). Amer. F. Med. 6, 684.

ZARembski, P. M. \& Hodgkinson, A. (I965a). Biochem. F. 96, 2 I8.

ZAREMBSKi, P. M. \& Hodgkinson, A. (1965b). Biochem. F. 96, 7 I4.

\section{UPPER URINARY TRACT IN PATIENTS AFTER TRAUMATIC SPINAL CORD INJURY}

By T. Najenson, M.D., L. Mendelson, M.D., H. Sabransky, M.D., H. Selibiansky, M.D., E. Jakubovitch, M.D., P. Solzi, M.D., J. Lazebnik, M.D. and S. Pikielny, M.D.

University of Tel Aviv School of Medicine and Loewenstein Rehabilitation Hospital, Raanana, Israel

POST-MORTEM evaluations show repeatedly a high frequency of renal damage among patients who suffered spinal cord injuries. As a result, renal deficiency is assumed to be an important factor in determining the cause of these patients' death (Barber and Cross 1952; Dietrick and Russi, I958; Bunts, I959; Comarr, 196I; Pearce et al., 1964; Talbot, I966; Nyquist and Bors, 1967).

Functional renal studies, done to confirm the above-mentioned assumption, revealed varying degrees of renal insufficiency in chronic cases of spinal cord injuries (Morales, 1956; Pennisi et al., I959; Doggart et al., I963; Price et al., I966). This renal insufficiency was related to chronic pyelonephritis alone or associated with both pyelonephritis and amyloidosis (Dalton, 1965). Since both of the above processes are thought to be related to infections, anti-bacterial prevention and treatment should be sufficient to reduce renal failure. The picture which emerges from the above argument is that urinary tract infections lead to pyelonephritis which is sometimes associated with amyloidosis, resulting in renal deficiency and death.

The most problematical link in this causal chain is the concept of pyelonephritis. Chronic pyelonephritis is a morphological concept; according to current views, it is not necessary that the cause of the morphological changes, which are associated with this concept, be infection and therefore it is possible that there may be causes of renal deficiency other than infection (Kimmelstiel, I964; Kalmanson et al., I965; Haveerstadt et al., 1966; Freedman, 1967; Angell et al., 1968). It is also possible that some of these anatomical changes occur without their being immediately expressed as renal insufficiency. 